\title{
Effect of Mechanical Milling on the Microstructure and Morphology of $\mathrm{Al}_{2024} / \mathrm{SiC}$ Nanocomposite
}

H. Barriga-Calvillo ${ }^{1,2}$, E. Lozano-Rodríguez ${ }^{1}$, I. Estrada-Guel ${ }^{2}$, M. Neri-Flores ${ }^{2}$, C. López-Meléndez ${ }^{3}$ and R. Martínez-Sánchez ${ }^{2}$, C. Carreño-Gallardo².

${ }^{1 .}$ Instituto Tecnológico de Chihuahua, Ave. Tecnológico \#2909, C.P. 31310 Chihuahua, Chih., México.

2. Centro de Investigación en Materiales Avanzados (CIMAV), Laboratorio Nacional de Nanotecnología-Chihuahua. Miguel de Cervantes No. 120, CP 31109. Chihuahua, México.

3. Universidad La Salle Chihuahua, Prol. Lomas de Majalca No. 11201, C.P. 31020 Chihuahua, México.

Aluminum based metal matrix composites are used in aerospace, defence and selected automotive applications such as high performance racing applications [1]. The most commonly used materials as reinforcement are $\mathrm{SiC}, \mathrm{Al}_{2} \mathrm{O}_{3}$ or $\mathrm{B}_{4} \mathrm{C}$ into the aluminum matrix. These materials are used to improve elastic modulus, enhanced heat and wear resistance [2]

A huge variety of research has been focused on the synthesis and application of metal matrix composites (MMC) in recent years. Metal and Ceramic particles have mainly been used as reinforcing materials. Aluminum and its alloys have been reinforced with ceramics in order to improve properties like wear behavior or mechanical strength [3]. However, most of them are related to the use of micron sized particles.

The purpose of the present studies is to investigate the influence of MM processing on the particle size, crystallite size and microstructural changes in powder particles and distribution of SiCp reinforcement.

Aluminum alloy $\mathrm{Al}_{2024}(\mathrm{Al}-4.00 \% \mathrm{Cu}-0.83 \% \mathrm{Mg}-0.21 \% \mathrm{Fe}-0.67 \% \mathrm{Mn}-0.12 \% \mathrm{Si}-0.03 \% \mathrm{Cr}$ ) was used as a matrix of composites and silicon carbide nanoparticles $\left(\mathrm{SiC}_{\mathrm{NP}}\right)$ as reinforcement. $\mathrm{SiC}_{\mathrm{NP}}$ were dispersed into the aluminum matrix to form the nanocomposites by a milling process. $\mathrm{Al}_{2024}$ was received as a metal bar, where debris, were obtained by drilling it. The milling times were 1, 2, 3, 4, 5, 7, 10,15 and $30 \mathrm{~h}$.

The $\mathrm{Al}_{2024}$ powder was produced by machining a solid extruded bar. The machined metal shavings were mixed with $\mathrm{SiC}_{\mathrm{NP}}$ in different concentrations (0.00, 0.50, 1.00, 1.50, 2.00, 2.50, 5.00 and 7.00 wt. \% $\mathrm{SiO}_{2} \mathrm{NP}$ ). Mixtures were mechanically milled in a high- energy ball mill SPEX8000 under argon atmosphere. Milling products were cold consolidated at $330 \mathrm{MPa}$ by a cylindrical steel die (compacting device) in order to obtain samples with $5 \mathrm{~mm}$ of diameter and $10 \mathrm{~mm}$ high. Green products were pressure-less sintered for $3 \mathrm{~h}$ at $500^{\circ} \mathrm{C}$.

Figure 1 shows the variation of crystallite size the matrix aluminum alloy 2024 as a function of milling time. It may be noted that the crystallite size was reduced from $280 \mathrm{~nm}$ in the reference sample $(0 \mathrm{~h}$ milling time) to about $19 \mathrm{~nm}$ after milling for $30 \mathrm{~h}$.

Figure 2 presents the SEM micrographs showing the morphology and size of the $\mathrm{Al}_{2024} / \mathrm{SiC}$ nanocomposites powder after milling for different times. The average particle size of $\mathrm{Al}_{2024} / \mathrm{SiC}$ nanocomposites, in the first hour of milling time, was calculated to be $101 \mu \mathrm{m}$, which reduced to 68,58 , 47, 32, 24, 16 and $9 \mu \mathrm{m}$, respectively after milling for $2,3,4,5,7,10,15$ and $30 \mathrm{~h}$, respectively. 
In the present investigation, we are dealing with ductile $\mathrm{Al}$ alloy and brittle $\mathrm{SiC}_{\mathrm{NP}}$ phases. During the initial stages of milling, the soft phase powder particles will get flattened and the brittle phase will get fragmented. Subsequently, with continued milling, the fine brittle particles will continue to decrease in their size and will get occluded on to the softer flattened particles. With further milling, these brittle particles get continuously kneaded and the particles get uniformly dispersed in the matrix. Also similar situation is observed in the present investigation, as confirmed by the SEM images.

References:

[1] Hurley S, MMCs Find Broad Range of Niche Markets, Met. Bull. Mon. (1995) 54-56.

[2] Otsuki M S, Kakehashi S, Kohno T, Advances in Powder Metallurgy, 2, Metal Powder Industries.

[3] C. L. De Castro, B.S. Mitchell, Crystal growth kinetics of nanocrystalline aluminum prepared by mechanical attrition in nylon media, Mater Sci Eng A 396 (2005) 124-128.

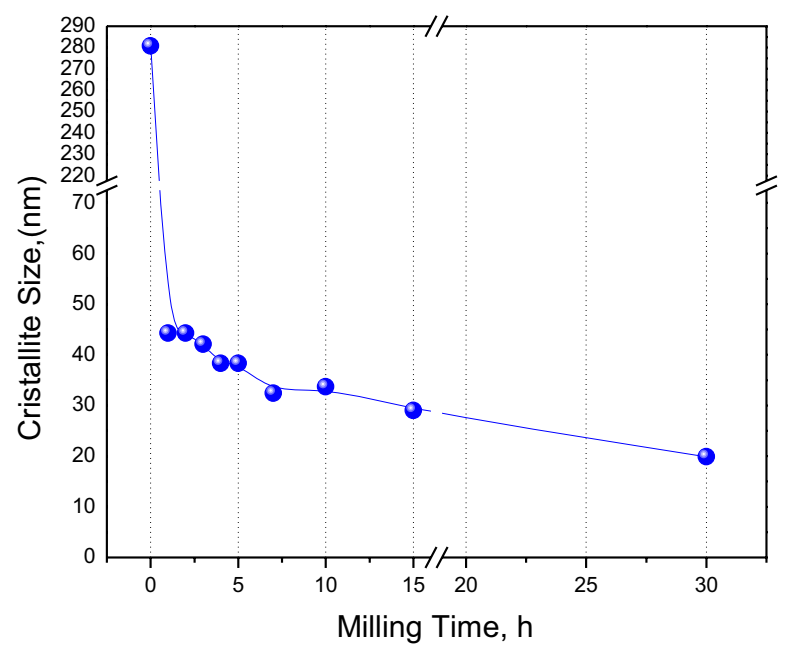

Figure 1. Graph showing crystallite size (CS) for $\mathrm{Al}_{2024} / \mathrm{SiC}$ nanocomposites containing 2.0, wt.\% $\mathrm{SiC}$ milled for $0,1,2,3,4,5,7,10,15,30 \mathrm{~h}$.

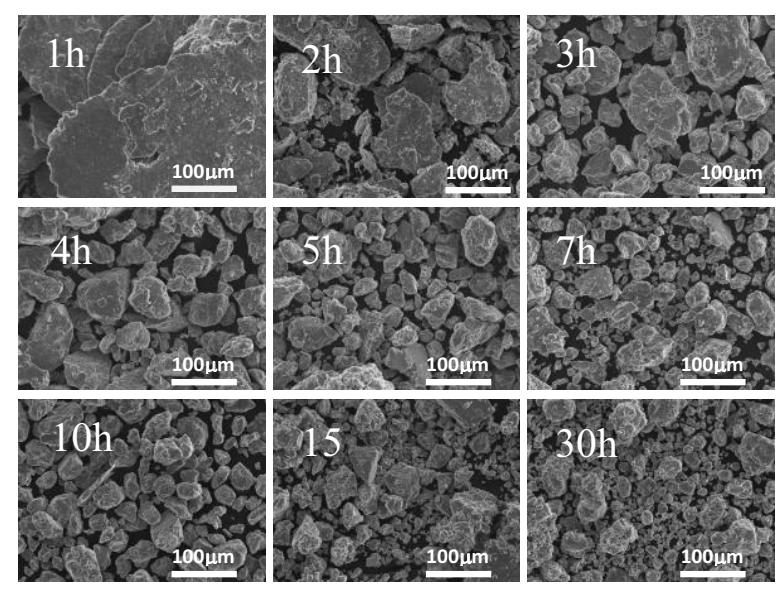

Figure 2. SEM micrographs of $\mathrm{Al}_{2024} / \mathrm{SiC}_{\mathrm{NP}}$ particle size milled for $1,2,3,4,5,7,10,15$ and $30 \mathrm{~h}$. shows the variation of size as a function of milling time. 